\title{
Influence of the Labeling Group on Ionization and Fragmentation of Carbohydrates in Mass Spectrometry
}

\author{
Erika Lattová,* Sergei Snovida, and Hélène Perreault \\ Department of Chemistry, University of Manitoba, Winnipeg, Manitoba, Canada \\ Oleg Krokhin \\ Physics and Astronomy Department, University of Manitoba, Winnipeg, Canada
}

The ionization and fragmentation behaviors of carbohydrate derivatives prepared by reaction with 2-aminobenzamide (AB), 1-phenyl-3-methyl-5-pyrazolone (PMP), and phenylhydrazine $(\mathrm{PHN})$ were compared under identical mass spectrometric conditions. It has been shown that the intensities of signals in MS spectra depend on the kind of saccharides investigated and reducing end labels used. PMP sialyllactose, when ionized by ESI/MALDI, produced a mixture of $[\mathrm{M}+\mathrm{H}]^{+},[\mathrm{M}+\mathrm{Na}]^{+},[\mathrm{M}-\mathrm{H}+2 \mathrm{Na}]^{+}$ions in the positive mode and $[\mathrm{M}-\mathrm{H}]^{-}$, $[\mathrm{M}+\mathrm{Na}-2 \mathrm{H}]^{-}$ions in the negative mode. The $\mathrm{AB}$ and $\mathrm{PHN}$ derivatives formed abundant $[\mathrm{M}+\mathrm{H}]^{+}$and $[\mathrm{M}-\mathrm{H}]^{-}$ions in ESI, and by matrix-assistend laser desorption/ionization (MALDI) produced abundant $[\mathrm{M}+\mathrm{Na}]^{+}$ions. PMP- and reduced AB-sialyllactose produced only Y-type fragment ions under both MS/MS sources. In the electrospray ionization (ESI)-MS /MS spectrum of PHN-sialyllactose, abundant ions corresponded to B, Z cleavages and in its MALDI-MS/MS spectrum, the abundant ions were consistent with $\mathrm{Y}$ glycosidic cleavages with the concurrence of B, C, and cross-ring fragment ions. In the MALDI-MS spectra of oligosaccharides acquired immediately after derivatization, it was possible to detect only PHN derivatives. After purification, spectra of all three types of derivatives showed high signal-to-noise ratios with the most abundant ions observed for $\mathrm{AB}$ reduced saccharides. $\mathrm{M}+$ $\mathrm{Na}]^{+}$ions were the dominant products and their fragmentation patterns were influenced by the type of the labeling and the kind of oligosaccharide considered. In the MALDI-PSD and -MS/MS spectra of AB-derivatized glycans, higher $\mathrm{m} / \mathrm{z}$ fragment ions corresponded to B and $\mathrm{Y}$ cleavages and the loss of bisecting GlcNAc appeared as a weak signal or was not detected at all. Fragmentation patterns observed in the spectra of hybrid/complex PHN and PMP glycans were more comparable-higher $\mathrm{m} / \mathrm{z}$ fragments corresponded to $\mathrm{B}$ and $\mathrm{C}$ glycosidic cleavages. For PHN glycans, the abundance of ions resulting from the loss of bisecting GlcNAc depended on the number of residues linked to the 6-positioned mannose. Also, PHN and PMP derivatives produced cross-ring cleavages with abundances higher than observed in the spectra of $\mathrm{AB}$ derivatized oligosaccharides. For high-mannose glycans, the most informative cleavages were provided by AB and PHN type of labeling. Here, PMP produced dominant Y-cleavages from the chitobiose while other ions produced weak signals. (J Am Soc Mass Spectrom 2005, 16, 683-696) (c) 2005 American Society for Mass Spectrometry

$\bigcup^{2}$ accharides, either free or as constituents of glycoproteins, proteoglycans, and glycolipids, are mediators for extracellular and intracellular recognition, cell differentiation and all proliferation [1, 2]. Glycosylation is also highly sensitive to alterations of cellular function, and altered protein glycosylation is diagnostic of a number of disease states including, for example, rheumatoid arthritis and cancer [3]. Therefore,

Published online March 11, 2005

Address reprint requests to Dr. H. Perreault, Department of Chemistry, University of Manitoba, 144 Dysart Road, Winnipeg, Manitoba R3T 2N2, Canada. E-mail: perreau@cc.umanitoba.ca

* Also at the Institute of Chemistry, Slovak Academy of Sciences, 84238 Bratislava, Slovakia. the growing interest in understanding the biological functions of carbohydrates has stimulated the development of methods for their improved analysis.

In order to detect saccharides by UV/fluorescence and also to ease their characterization by mass spectrometry (MS), introducing a chromophore into the molecules has received increasing attention. In this respect, a large number of derivatization procedures for mono- and oligosaccharides have been described in the literature, most of which have been detailed in a recent review [4]. For example, 2-aminoacridine (2-AMAC) as a sensitive fluorophore, has been used for the detection of monosaccharides, and of neutral and charged oligosaccharides by electrospray ionization (ESI) and matrix- 
a)

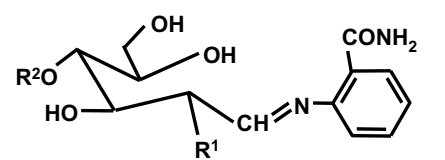<smiles>[C]1CC1</smiles>

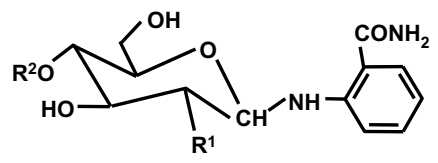

b)

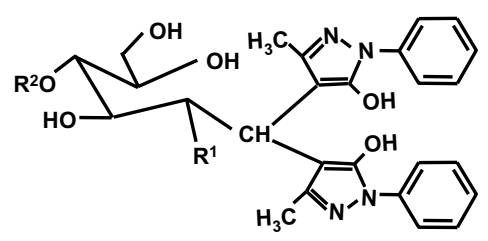

c)

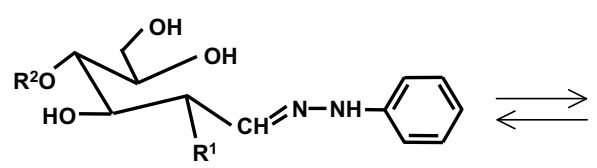

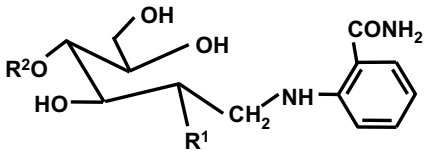

$\mathbf{R}^{1}$

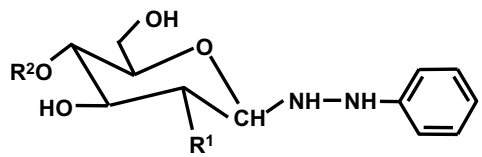

Scheme 1. Structures of aminobenzamide (AB) (a), pyrazolone (PMP) (b), and phenylhydrazone (PHN) (c) derivatives of oligosaccharides.

assisted laser desorption/ionization (MALDI) MS [5, 6]. Another reagent, 3-acetamido-6-aminoacridine (AAAc), has been used for analysis of $\mathrm{N}$-linked glycans at the picomole level and yielded in higher sensitivities then AMAC [7]. Also, the 2-(diethylamino)ethyl ester of 4-aminobenzoic acid was shown to increase the sensitivity 1000 -fold relative to underivatized glycans under MALDI-MS conditions [8]. As another example, 9-aminofluorene was investigated as a label for linear and branched oligosaccharides, and the smallest amount that could be detected was 5 pmol by photodiode array UV [9]. Among other derivatization agents frequently used are 2-aminopyridine (AP) [10, 11], 4-aminobenzoic acid ethyl ester (ABAEE) [12], 2-aminobenzamide $(\mathrm{AB})[13,14]$, and 2-aminobenzoic acid (ABA), the latter producing good negative ion MALDI spectra [15]. Each derivatization procedure has its advantages and inconveniences, depending on the class of carbohydrates investigated and on the amount/complexity of the sample, among other factors.

Most reactions of saccharides with amino compounds are followed by reduction, providing open ring structures at the former reducing ends. Omitting the sodium cyanoborohydride reducing step produces less stable Schiff bases. Both types of derivatives were previously examined under ESI-MS conditions [16]. Results presented in the previous study [16] showed that the type of reducing-end derivative could affect the abundance and nature of ions formed, but that it had little effect on the fragmentation pattern. Reduced
2-AMAC derivatives yielded the most intense MALDI signals, however, this labeling method produced the least informative fragmentation patterns because of the preferential formation of $Y_{1}$ and $Y_{2}$ species. The corresponding unreduced derivatives (Schiff bases/glycosylamines) produced fragmentation patterns similar to those of the reduced, however, they were very unstable and reaction yields were low in general. In other articles, it has been shown that unreduced alkylamine derivatives of monosaccharides exist as closed-ring glycosylamines [17]. These compounds have been used to facilitate chromatographic and MS analysis of saccharides $[18,19]$. Besides, closed-ring derivatives provided improved structural information on linkage and anomeric configuration. Unreduced glycosylamine derivatives were also preferred over reduced derivatives for the purposes of determining sulfation and uronic acid positions in chondroitin sulfate saccharides [20].

In the present article, three tagging methods were compared (see Scheme 1). First, aminobenzamidation was selected because of its popularity and usefulness [13], second, derivatization with 1-phenyl-3-methyl-5pyrazolone (PMP) yielding bis-PMP products [21] was chosen because of their frequent use in our laboratory [22], and third, unreduced phenylhydrazone derivatives were selected because of the simplicity of the procedure and very informative fragmentation observed under MALDI-MS conditions [23,30]. The purpose of this study was to compare how different labeling groups at the reducing end of saccharides can 


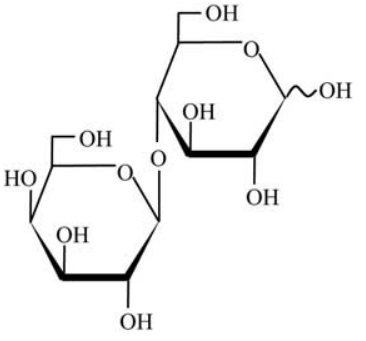

Lactose

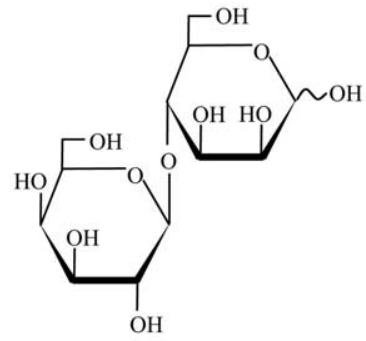

Epilactose

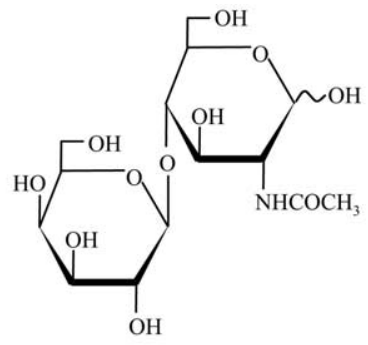

N-Acetyllactosamine
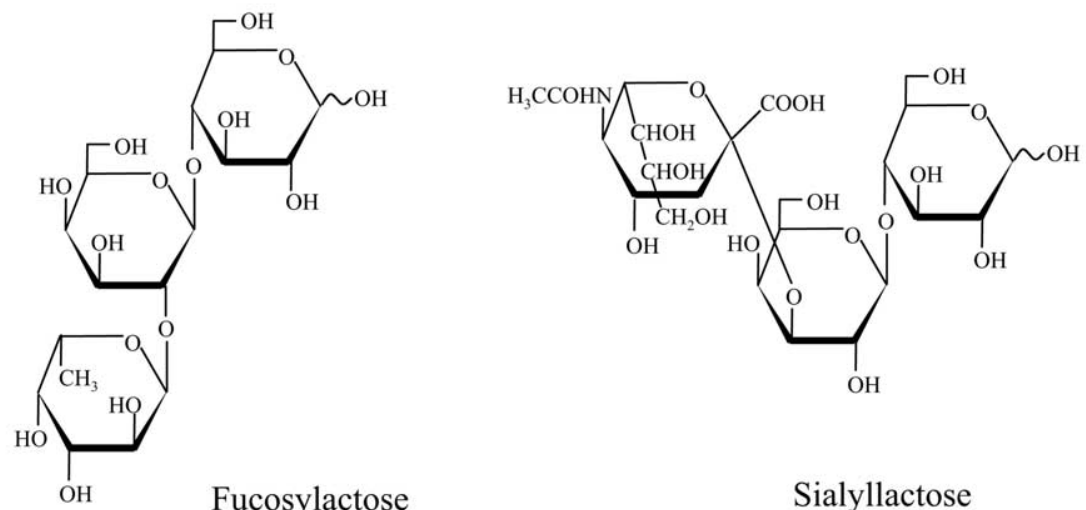

Scheme 2. Structures of the small saccharides used in this study.

influence sensitivity, ionization efficiency, and fragmentation behavior. The emphasis was placed on fragmentation data that provide specific information, such as antenna composition and possible differentiation of isomeric structures among oligosaccharides. Small saccharides-lactose, $\mathrm{N}$-acetyllactosamine, fucosyllactose, and sialyllactose-were studied under ESI- and MALDI-MS conditions. Large oligosaccharides, because of limited amounts, were characterized only by MALDI-MS.

\section{Experimental}

\section{Materials}

Anthranilamide, sodium cyanoborohydride, phenylhydrazine, hen ovalbumin (Grade V), $\beta$-lactose $(\beta$-DGal-1 $\rightarrow 4$-D-Glc), epilactose $(\beta$-D-Gal-1 $\rightarrow 4-D-M a n)$, 2 'fucosyllactose $(\beta$-L-Fuc1 $\rightarrow 2-\beta$-D-Gal- $1 \rightarrow 4-\mathrm{D}-\mathrm{Glc})$, sialyllactose (a mixture of $3^{\prime}$ - and $6^{\prime}$-N-acetylneuramin-lactose), dimethyl sulfoxide, and 2,5-dihydroxybenzoic acid matrix (DHB) were purchased from Sigma (St. Louis, MO). Sialylated oligosaccharide SC1123 was obtained from V-LABS (Covington, LA). The reagent 1-phenyl-3-methyl-5-pyrazolone was purchased from ICN Biomedicals Inc. (Aurora, $\mathrm{OH})$. $\mathrm{N}$-acetyllactosamine was prepared according to a published procedure [25]. Peptide- $N$-glycosidase F (PNGase F) deglycosylation kits and GlycoClean S cartridges were purchased from Prozyme (San Lean- dro, CA). Solvents (acetonitrile, ethanol, ethyl acetate, chloroform, methanol) were HPLC-grade and purchased from Fisher Scientific (Fair Lawn, NJ). HPLCgrade deionized distilled water was obtained with a Milli-Q plus TOC water purification system (Millipore, Bedford, MA).

\section{Deglycosylation by PNGaseF Digestion [26, 27]}

The glycoprotein $(\sim 500 \mu \mathrm{g})$ was dissolved in deionized water $(36 \mu \mathrm{L})$ in a micro centrifuge tube, and Buffer $5 \times$ supplied with the Glyko deglycosylation kit was added $(9 \mu \mathrm{L})$. The glycoprotein was denatured by boiling in a hot water-bath for $10 \mathrm{~min}$. After cooling, PNGase F enzyme $(2 \mu \mathrm{L})$ was added and the mixture was incubated at $37^{\circ} \mathrm{C}$ for $18 \mathrm{~h}$. The protein was precipitated by adding four volumes of cold ethanol and the mixture was kept in ice $(\sim 2 \mathrm{~h})$. The $N$-deglycosylated protein was centrifuged down to a pellet and the supernatant containing the oligosaccharides was pipetted out into another micro centrifuge tube. Ethanol was evaporated and the white residue was derivatized as described below.

\section{2-Aminobenzamide $(A B)$ Derivatives}

$(1)^{\circ}$ Reduced $^{\circ} \mathrm{AB}^{\circ}$ derivatives ${ }^{\circ}[13]^{\circ}$ were $^{\circ}$ prepared $^{\circ}$ by dissolving the saccharides (up to $0.5 \mu \mathrm{mol}$ ) in $2 \mathrm{AB}$ solution $(50 \mu \mathrm{L}): 2 \mathrm{AB}$ reagent $(5 \mathrm{mg})$ and $\mathrm{NaBH}_{3} \mathrm{CN}$ $(7.5 \mathrm{mg})$ in DMSO $(500 \mu \mathrm{L})$ and acetic acid $(200 \mu \mathrm{L})$. 


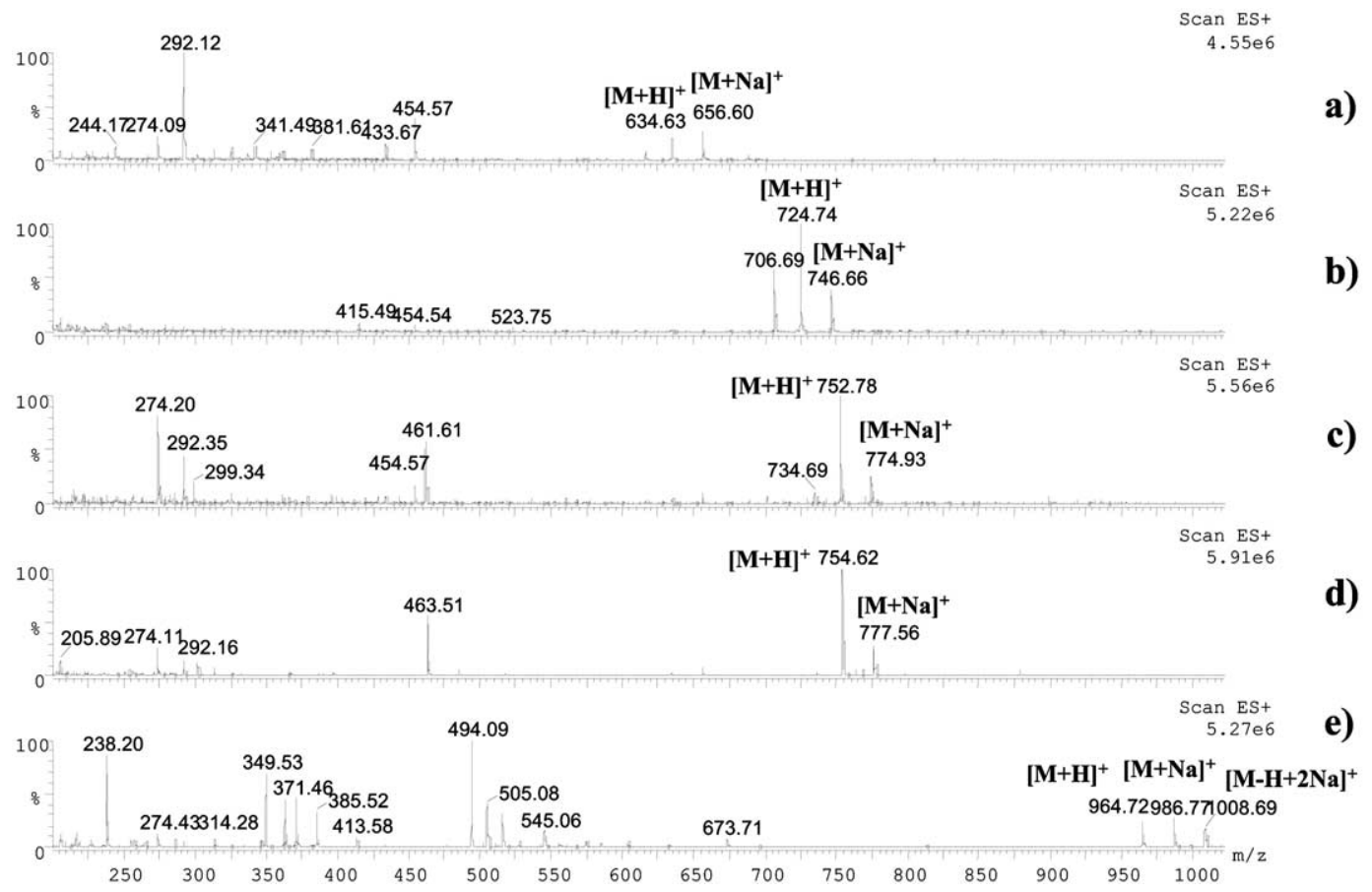

Figure 1. Positive ESI-MS spectra of sialyllactose: Native form (a), derivatized with PHN (b), AB-unreduced (c), AB-reduced (d), and PMP (e).

The reaction mixture was heated at $65^{\circ} \mathrm{C}$ for $2.5 \mathrm{~h}$. After incubation, the samples were cleaned using GlycoClean $\mathrm{S}$ cartridges according to the accompanying protocol.

(2) Unreduced $A B$ derivatives were prepared by dissolving the saccharide (up to $0.5 \mu \mathrm{mol}$ ) in $10 \mu \mathrm{L}$ of water and $30 \mu \mathrm{L}$ of reagent solution made by dissolving $2 \mathrm{AB}(10 \mathrm{mg})$ in methanol $(100 \mu \mathrm{L})$ and reacting at $75^{\circ} \mathrm{C}$ for $3 \mathrm{~h}$ with frequent mixing. Then methanol was evaporated and an additional $200 \mu \mathrm{L}$ of water was added and the solution was washed with chloroform (2 $\times 20 \mu \mathrm{L}$ ) to remove excess $\mathrm{AB}$ reagent.

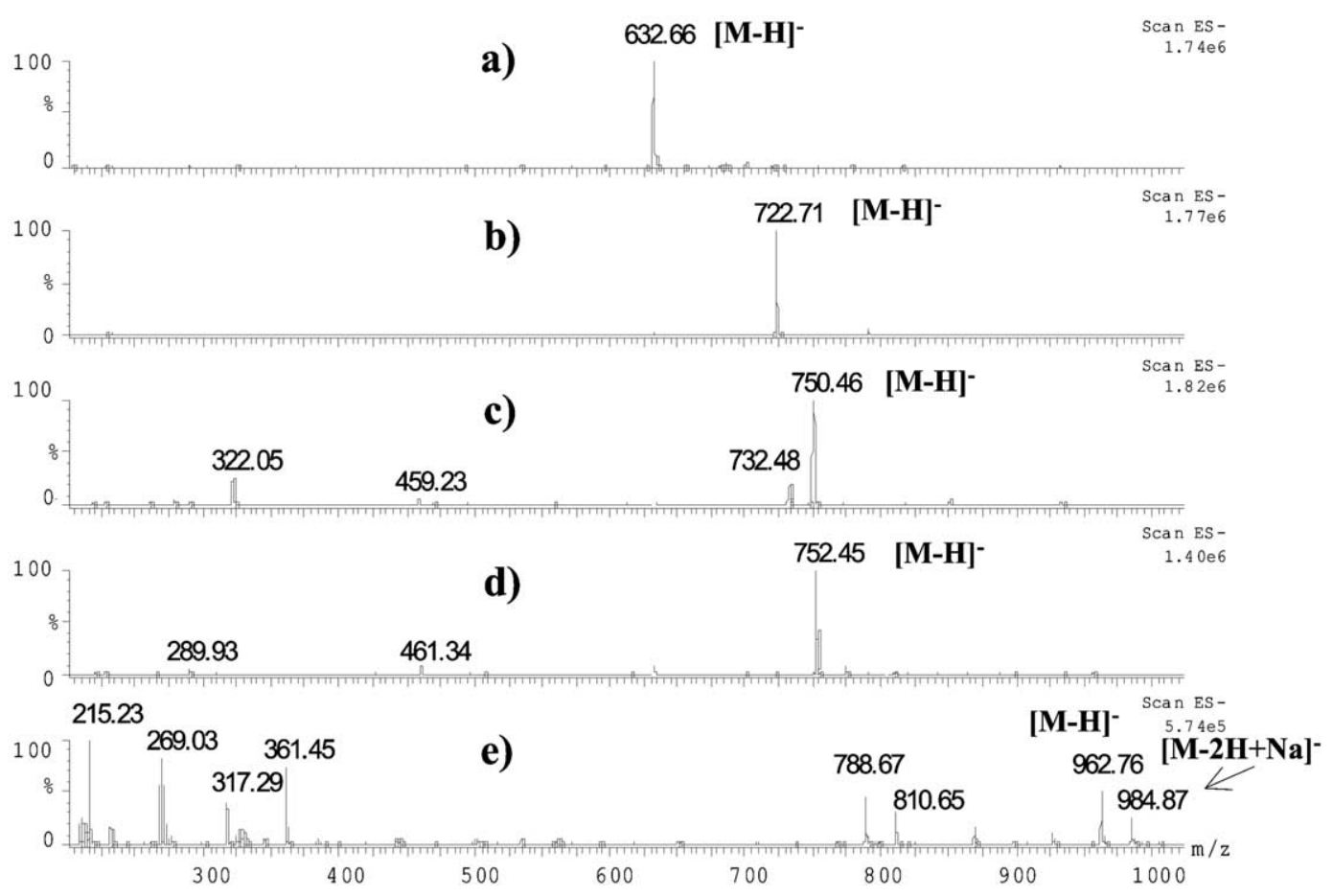

Figure 2. Negative ESI-MS spectra of sialyllactose: Native form (a), derivatized with PHN (b), AB-unreduced (c), AB-reduced (d), and PMP (e). 


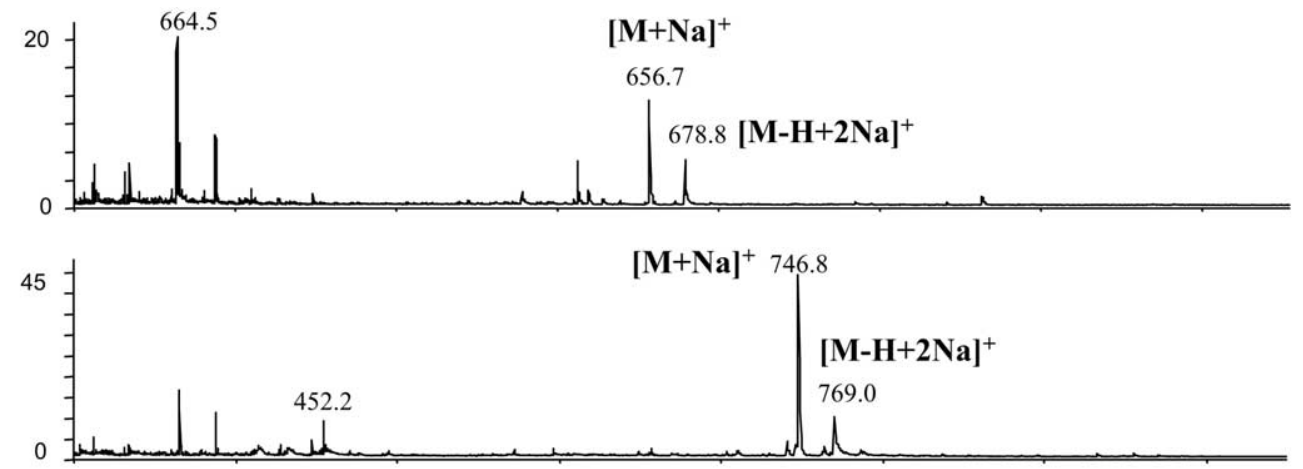

a)

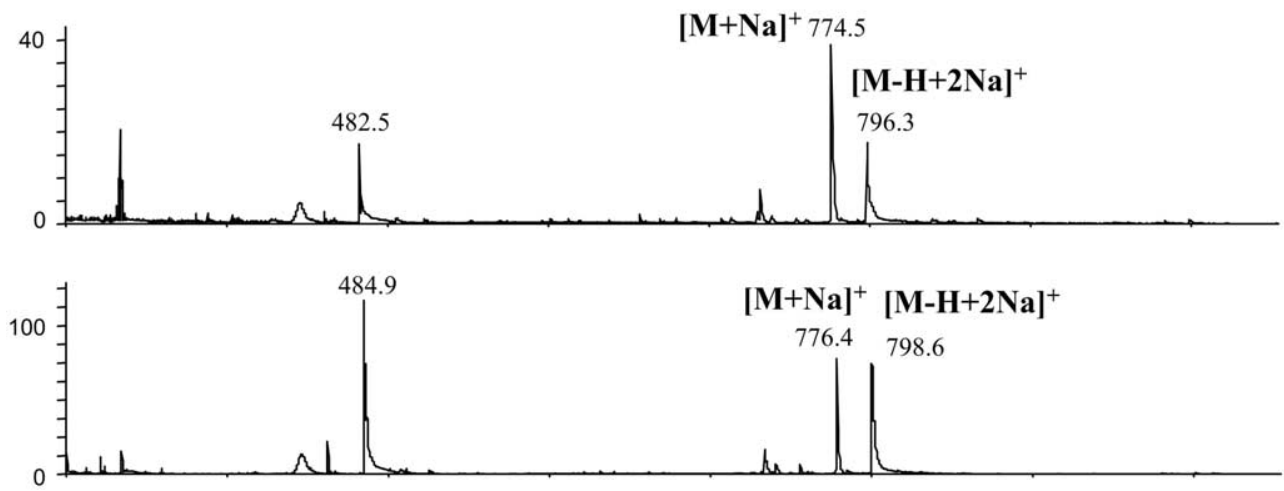

c)

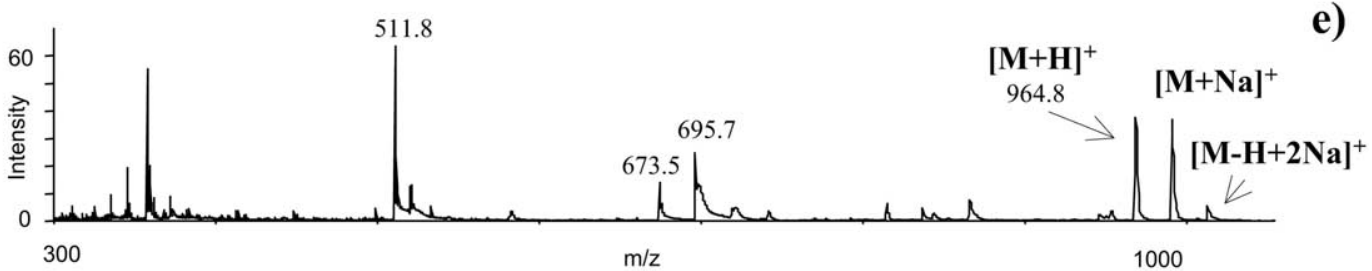

Figure 3. Positive MALDI-MS spectra of siallylactose acquired on a Biflex-IV spectrometer for: Native form (a), derivatized with PHN (b), AB-unreduced (c), AB-reduced (d), and PMP (e).

\section{1-Phenyl-3-Methyl-5-Pyrazolone Derivatives $(P M P)$}

The saccharides (up to $0.5 \mu \mathrm{mol}$ ) were dissolved in 0.3 $\mathrm{M} \mathrm{NaOH}(30 \mu \mathrm{L})$, followed by addition of $0.5 \mathrm{M}$ methanolic PMP solution $(30 \mu \mathrm{L})$. Mixtures were heated to $70{ }^{\circ} \mathrm{C}$ for $30 \mathrm{~min}$ and then neutralized with $0.3 \mathrm{M}$ of $\mathrm{HCl}^{\circ}\left(30^{\circ} \mu \mathrm{L}\right)^{\circ}[21] .{ }^{\circ}$ More $^{\circ}$ water $^{\circ}$ was $^{\circ} \operatorname{added}^{\circ}\left(200^{\circ} \mu \mathrm{L}\right)^{\circ}$ and the excess PMP reagent was removed by extraction with chloroform $(20 \mu \mathrm{L})$ or purification was achieved using a GlycoClean S cartridge.

\section{Phenylhydrazone Derivatives (PHN)}

PHN derivatives of saccharides were prepared according ${ }^{\circ}$ to $^{\circ}{ }^{\circ}$ published ${ }^{\circ}$ procedure ${ }^{\circ}[23,24]$. Phenylhydrazine $(0.5-1 \mu \mathrm{L})$ was added to a water solution of saccharide (50 $\mu \mathrm{L}$; up to $0.5 \mu \mathrm{mol}$ ) and the mixture was incubated for $1 \mathrm{~h}$ at $80^{\circ} \mathrm{C}$ with frequent mixing. Then the samples were analyzed directly without removing the excess phenylhydrazine or after extraction with ethylacetate.
The ethylacetate layer was pipetted out to another tube and washed with water $(3 \times 20 \mu \mathrm{L})$. The water fractions were mixed together and completed to appropriate volume for analysis.

\section{ESI-Mass Spectrometry}

The mass spectrometer used for ESI experiments was a Quattro-LC (Micromass, UK) equipped with a Z-spray ion source and a triple quadrupole analyzer. Direct injections were carried out with a $20 \mu \mathrm{L}$ Rheodyne loop and the mobile phase solvent was acetonitrile/water (1:1). The source block and the desolvation temperatures were set at 110 and $130{ }^{\circ} \mathrm{C}$. The samples were sprayed using a $3.5 \mathrm{kV}$ needle voltage and the cone voltage was set to $20 \mathrm{~V}$. Mass spectra were recorded in the positive and in the negative ion modes with a scan rate of $300 \mathrm{Us}^{-1}$. MassLynx software. CID tandem MS experiments were conducted with argon, at a gas pressure of $3 \times 10^{-3}$ torr and collision energy of $28 \mathrm{eV}$. For all experiments, $5 \mu \mathrm{L}$ aliquots were injected. 


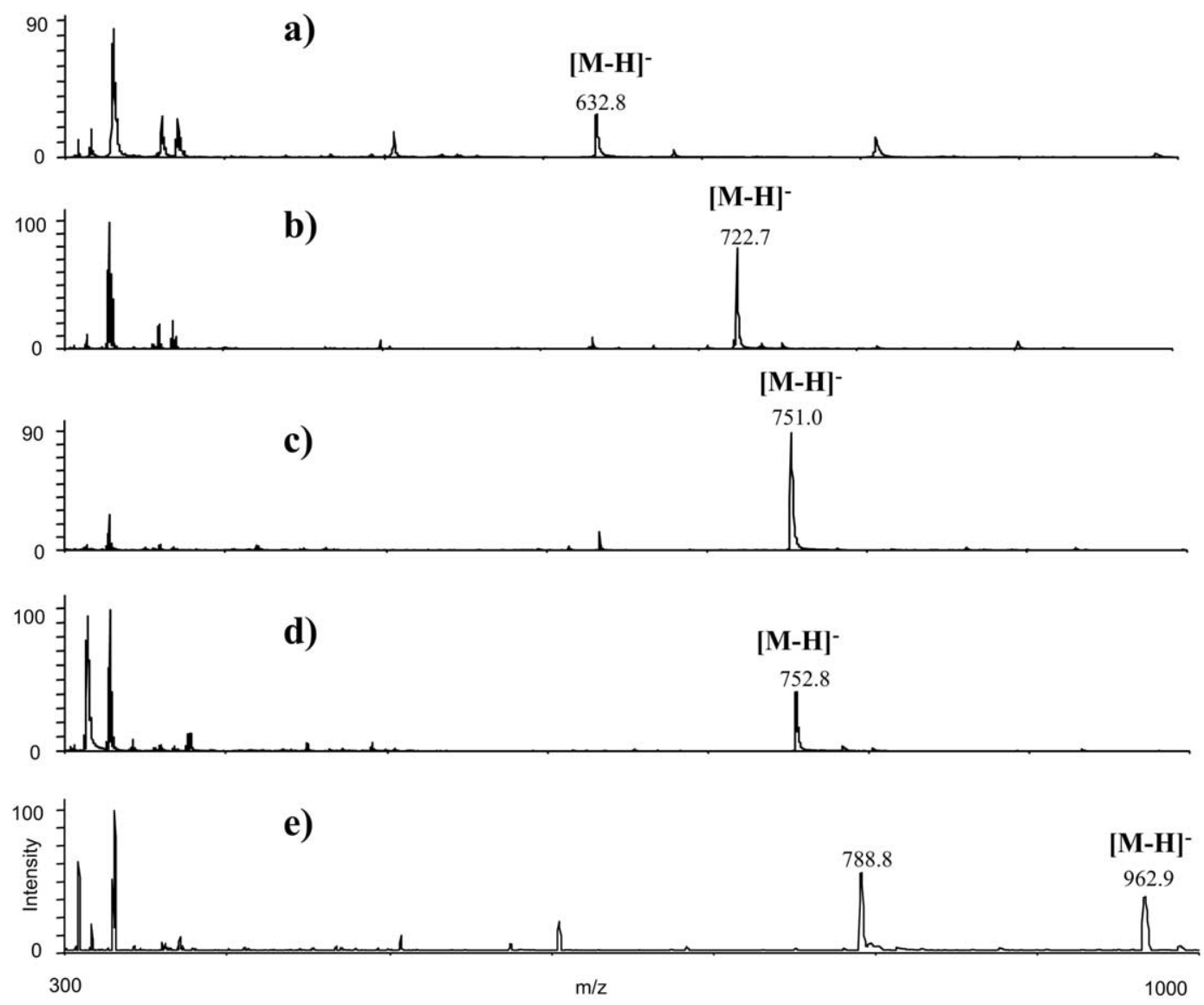

Figure 4. Negative MALDI-MS spectra of sialyllactose acquired on a Biflex-IV spectrometer: Native form (a), derivatized with PHN (b), AB-unreduced (c), AB-reduced (d), and PMP (e).

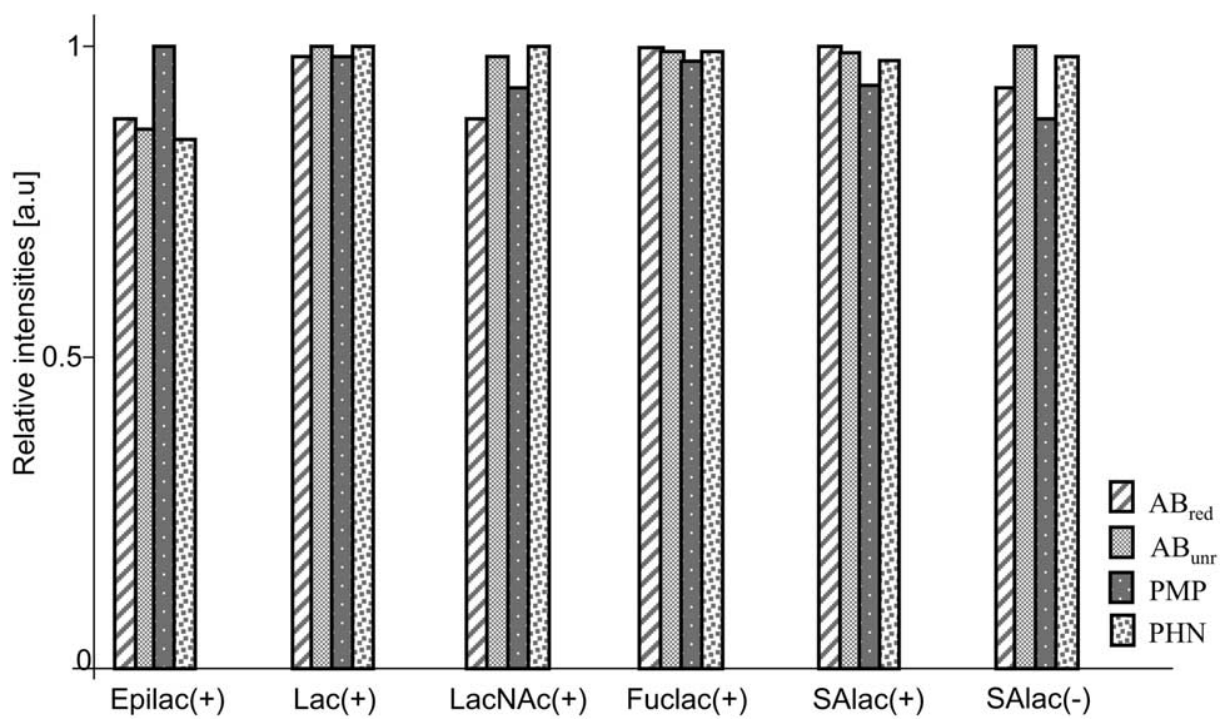

Figure 5. Comparison of ESI-MS ionic abundances observed for small derivatized carbohydrates in positive $(+)$ and negative $(-)$ modes. For each derivative, seven reactions were set up and ten measurements were taken on each product. The averages are reported. Percentage errors were on the order of $\pm 5 \%$. Values were obtained by adding $[\mathrm{M}+\mathrm{H}]^{+},[\mathrm{M}+\mathrm{Na}]^{+}$signals in the positive mode, and $[\mathrm{M}-\mathrm{H}]^{-},[\mathrm{M}-2 \mathrm{H}+\mathrm{Na}]^{-}$in the negative mode. 

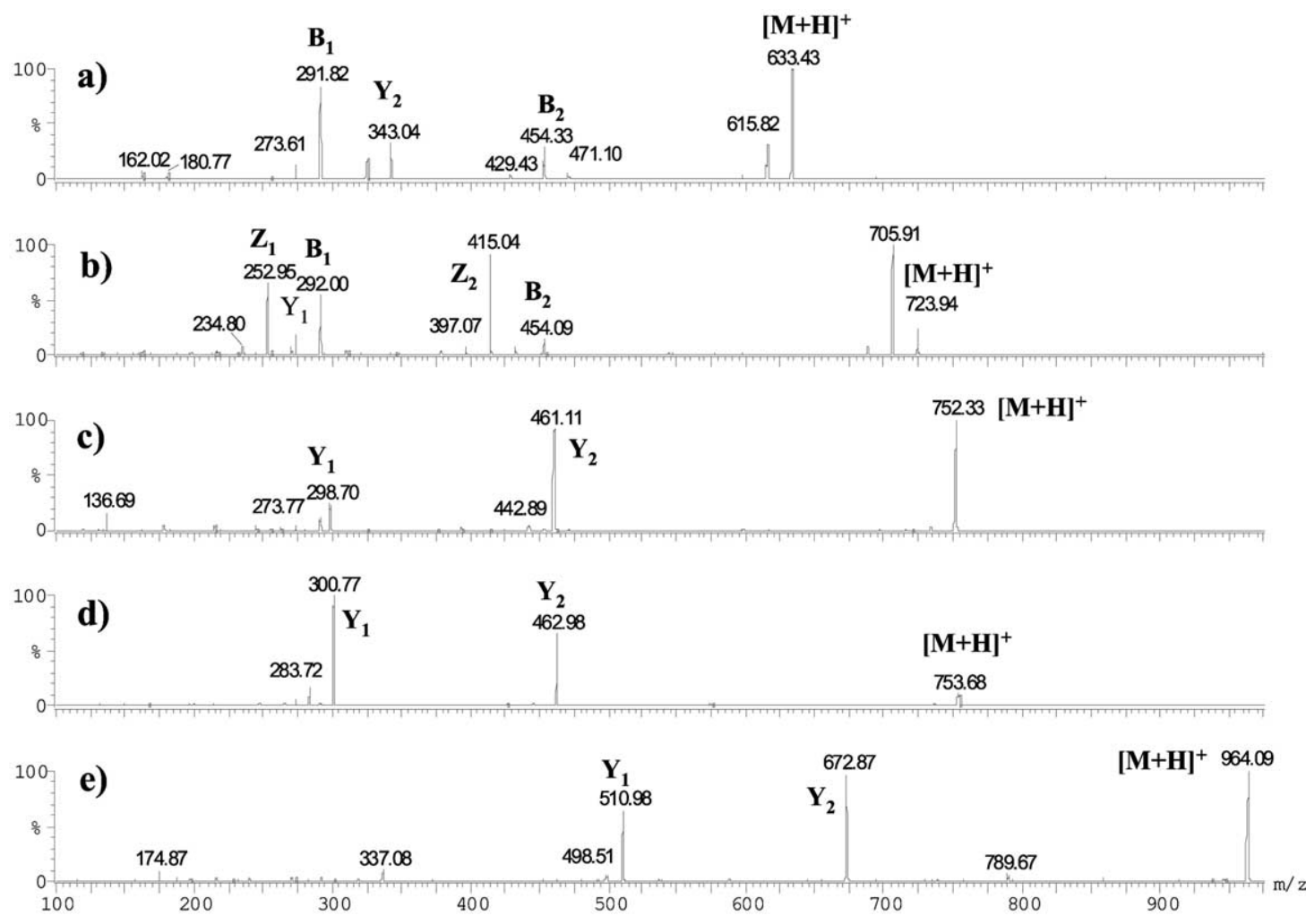

Figure 6. ESI-MS/MS spectra of $[\mathrm{M}+\mathrm{H}]^{+}$ions of sialyllactose detected in the native form (a), derivatized with PHN (b), AB-unreduced (c), AB-reduced (d), and PMP (e).

\section{MALDI-Time-of-Flight (TOF) Mass Spectrometry}

MALDI spectra were recorded on a Biflex-IV spectrometer (Bruker Daltonics, Billerica, MA). Profiling of the molecular ions of native and derivatized glycans was achieved in the positive mode, using linear and reflective TOF. The accelerating voltage was $20 \mathrm{kV}$. For sensitivity studies on derivatized oligosaccharides, each glycan pool was purified and dissolved in $20 \mu \mathrm{L}$ of distilled water and $0.5 \mu \mathrm{L}$ aliquots were loaded onto the target. The sum of 200 shots was collected for each spectrum. MALDI-PSD spectra were recorded in the positive ion mode with the laser power adjusted to $80 \%$ of its maximal intensity. MALDI-MS/MS spectra were acquired using a prototype quadrupole-quadrupole$\mathrm{TOF}^{\circ}(\mathrm{QqTOF})^{\circ}$ mass $^{\circ}$ spectrometer $^{\circ}[28]^{\circ}{ }^{\circ}$ In $^{\circ}$ this ${ }^{\circ}$ instrument, ions are produced by irradiation of the sample with photon pulses from a $20 \mathrm{~Hz}$ nitrogen laser (VCL 337ND, Spectra-Physics, Mountain View, CA) with 300 $\mathrm{mJ}$ energy per pulse. Parent ions were selected in the first quadrupole (Q1) after cooling, then broken up in the second rf-only quadrupole (q2) by CID at low energy. The collisional energy for each precursor ion was determined by applying a well-defined accelerating voltage at the entrance of the collisional cell, and values were around $50 \mathrm{eV}$ per each $1000 \mathrm{Da}$. Orthogonal injection of ions from the q2 into the TOF section routinely produces a mass resolving power of $\sim 10,000$ FWHM, and accuracy within a few $\mathrm{mDa}$, in both MS and MS/MS modes.
The samples were mixed with saturated matrix solution (DHB in acetonitrile/water 1:1), deposited on the surface of a MALDI target, air dried, and subjected to analysis.

\section{Results and Discussion}

$\mathrm{AB}, \mathrm{PMP}$, and PHN derivatives of saccharides were prepared according to published procedures with some variations as described in the experimental section. For example, in the preparation of unreduced $A B$ derivatives, the use of acetic acid was avoided and the reaction was performed in a water/methanol solution at increased temperature. These conditions helped to enhance yields, however, required more frequent mixing during incubation.

\section{Small Carbohydrates}

The relative sensitivities of detection for labeled lactose and analogs (Scheme 2) were compared under ESI and MALDI-MS conditions in the positive and negative modes. Using a low cone voltage, all three types of derivatives produced $[\mathrm{M}+\mathrm{H}]^{+},[\mathrm{M}+\mathrm{Na}]^{+},[\mathrm{M}-\mathrm{H}+$ $2 \mathrm{Na}]^{+}$ions in the positive mode and $[\mathrm{M}-\mathrm{H}]^{-},[\mathrm{M}-$ $2 \mathrm{H}+\mathrm{Na}^{-}$ions in the negative mode, with relative abundances depending on the method of ionization, the kind of label, and the purification procedure used after derivatization. While $\mathrm{AB}$ and $\mathrm{PHN}$ derivatives of lac- 


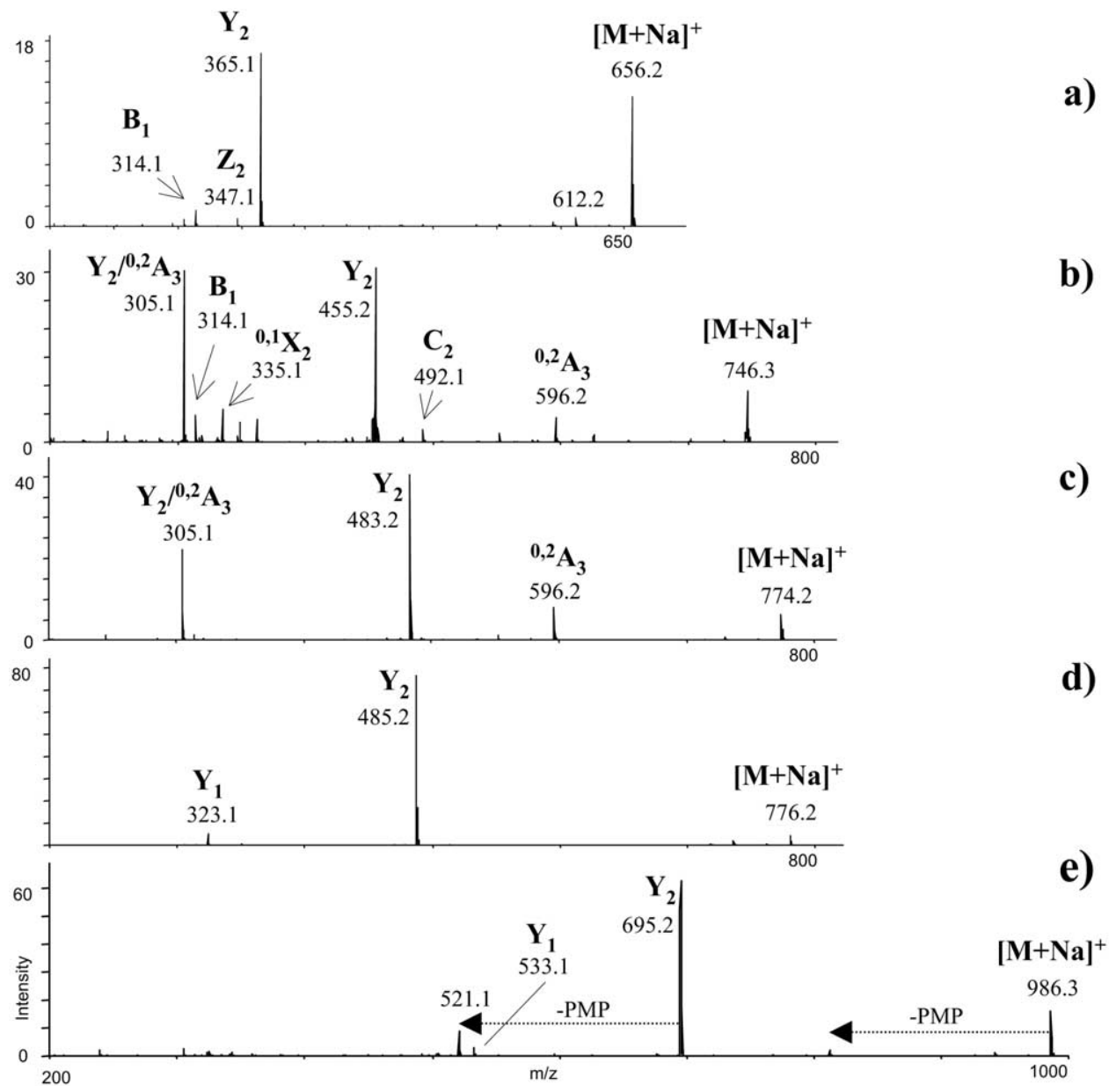

Figure 7. MALDI-MS/MS spectra of $[\mathrm{M}+\mathrm{Na}]^{+}$ions of sialyllactose acquired on a MALDI-QqTOF spectrometer and detected in the native form (a), derivatized with PHN (b), AB-unreduced (c), AB-reduced (d), and PMP (e).

tose, epilactose, N-acetyllactosamine, fucosyllactose, and sialyllactose ionized mainly as $[\mathrm{M}+\mathrm{H}]^{+} /[\mathrm{M}-$ $\mathrm{H}]^{-}$ions by ESI-MS and $[\mathrm{M}+\mathrm{Na}]^{+} /[\mathrm{M}-\mathrm{H}]^{-}$ions in MALDI-MS, PMP-sialyllactose in both ESI and MALDI arose as mixtures of $[\mathrm{M}+\mathrm{H}]^{+},[\mathrm{M}+\mathrm{Na}]^{+},[\mathrm{M}-\mathrm{H}+$ $2 \mathrm{Na}]^{+}$ions in the positive mode and $[\mathrm{M}-\mathrm{H}]^{-},[\mathrm{M}-$ $2 \mathrm{H}+\mathrm{Na}^{-}$ions in the negative mode, regardless on the

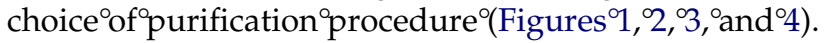
MS sensitivities depended not only on the label used but also on the kind of carbohydrate investigated. Epilactose produced the highest signal with PMP ( $\sim 10 \%$ over $\mathrm{AB}$ and $\mathrm{PHN})$, but lactose and fucosyllactose showed comparable sensitivities for all three derivatives. Figure 5 shows the ${ }^{\circ}$ values ${ }^{\circ}$ of added $\left[\mathrm{M}^{\circ}+\mathrm{H}^{\circ}{ }^{+}\right.$, $[\mathrm{M}+\mathrm{Na}]^{+}$signals (positive mode) and $[\mathrm{M}-\mathrm{H}]^{-},[\mathrm{M}-$ $2 \mathrm{H}+\mathrm{Na}]^{-}$signals (negative mode). For $\mathrm{N}$-acetyl lactosamine, stronger signals were observed for unreduced $A B$ and PHN derivatives than for their reduced analogs. In the case of sialyllactose, again $\mathrm{AB}$ and $\mathrm{PHN}$ yielded better sensitivity in the ESI-MS spectra in the positive and negative modes, however, no significant differences were observed between the $A B$ unreduced and ${ }^{\circ}$ reduced ${ }^{\circ}$ forms ${ }^{\circ}\left(\right.$ Figures $^{\circ} 1^{\circ}$ and 2 ). ${ }^{\circ}$ When ${ }^{\circ}$ derivatives of sialyllactose were examined by MALDI-MS in positive mode, on average the $A B$ derivatives yielded the most intense signals, however, the most abundant ions corresponded to the loss of sialic acid $(\mathrm{m} / \mathrm{z}$ at 484.9 , Figure $\left.^{\circ} 3 \mathrm{~d}\right) .{ }^{\circ}$ In ${ }^{\circ}$ negative ${ }^{\circ}$ mode ${ }^{\circ}$ MALDI-MS ${ }^{\circ}$ spectra, ${ }^{\circ}$ nonreduced $\mathrm{AB}$ and $\mathrm{PHN}$ derivatives of sialyllactose yielded the best signals for this compound, with no loss of $^{\circ}$ sialic $^{\circ}$ acid $^{\circ}$ (Figure ${ }^{\circ}$ ).

Next, the MS/MS fragmentation patterns of these derivatives were compared. In the ESI-MS/MS spectra of $[\mathrm{M}+\mathrm{H}]^{+}$ions of PMP- and AB-sialyllactose (reduced and unreduced forms), abundant Y-type fragment ions were observed (nomenclature of Domon and Costello [29]). In the ${ }^{\circ}$ spectrum ${ }^{\circ}$ f $P H N$-sialyllactose, the most abundant ions corresponded to $\mathrm{B}$ and $\mathrm{Z}$ cleavages (Figure ${ }^{\circ}$ ). ${ }^{\circ}$ Under ${ }^{\circ} \mathrm{MALDI}-\mathrm{MS} / \mathrm{MS}^{\circ} \mathrm{Conditions}^{\circ}{ }^{\circ}$ all ${ }^{\circ}$ three derivatives fragmented by $\mathrm{Y}_{2}$ cleavages of sialic acid (Figure $\left.{ }^{\circ} 7\right) .{ }^{\circ}$ In $^{\circ}$ the ${ }^{\circ}$ spectra ${ }^{\circ}$ of ${ }^{\circ}$ unreduced $^{\circ} \mathrm{AB}^{\circ}$ and ${ }^{\circ} \mathrm{PHN}$, abundant $\mathrm{Y}_{2} /{ }^{0,2} \mathrm{~A}_{3}$ internal fragment ions at $\mathrm{m} / \mathrm{z} 305.2$ appeared. A previous study on the fragmentation of chondroitin sulfates showed the advantage of using unreduced $\mathrm{AB}$ derivatives over pyridylamidation (PA) to avoid acid residue losses subsequent to $\mathrm{B}$ fragmen- 

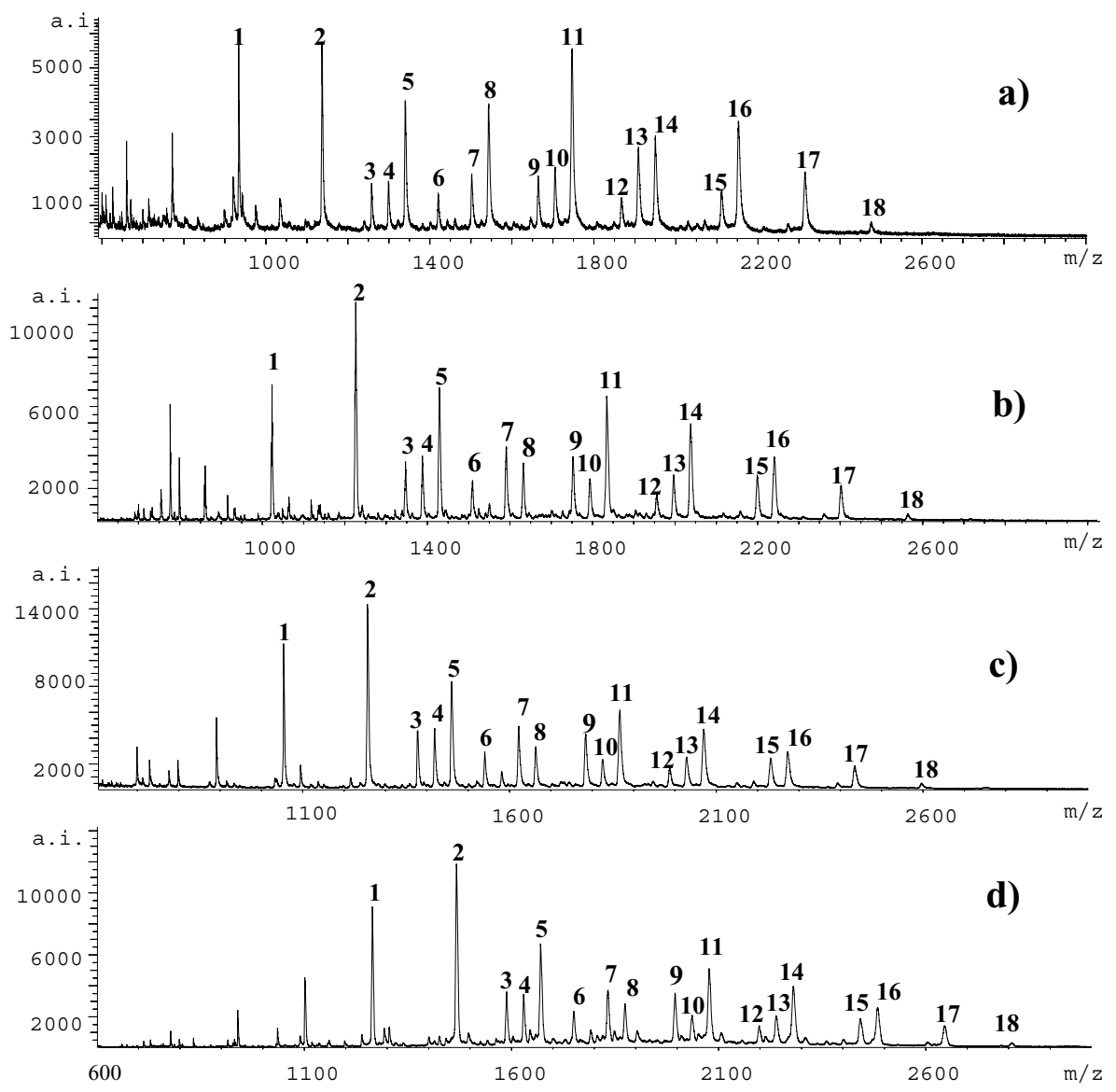

Figure 8. MALDI-MS spectra of the glycans released from ovalbumin: (a) Native forms, (b) PHN, (c) $\mathrm{AB}$, and (d) PMP derivatives.

tations ${ }^{\circ}[20] .{ }^{\circ} \operatorname{In}^{\circ}$ our $^{\circ} \mathrm{MS} / \mathrm{MS}^{\circ}$ spectra $^{\circ}$ of $^{\circ} \mathrm{AB}^{\circ}$ and $^{\circ} \mathrm{PMP}$ derivatized sialyllactose, however, no fragment ions appeared to have retained sialic acid. Only the spectra of native and PHN sialyllactose showed $\mathrm{B}_{1}$ ions at $\mathrm{m} / \mathrm{z}$

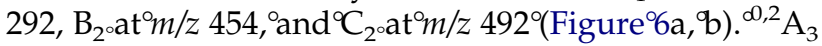
cross-ring cleavages were observed at $m / z 596$ in the MALDI-MS/MS spectra of unreduced $\mathrm{AB}$ and PHN derivatives ${ }^{\circ}\left(\text { Figure }^{\circ} 7 \mathrm{~b},{ }^{\circ} \mathrm{C}\right)^{\circ}$.

\section{Large Oligosaccharides}

In the MALDI-MS spectra of N-linked oligosaccharides from ovalbumin loaded onto the target immediately after derivatization, i.e., without further cleaning, it was possible to detect oligosaccharides only in the case of PHN derivatives. After purifying procedures, the spectra of all three types of derivatives had good signal-tonoise ratios, with the best observed for $\mathrm{AB}$ reduced glycans $^{\circ}\left(\right.$ Figure $\left.^{\circ} 8\right) .{ }^{\circ}\left[\mathrm{M}^{\circ}+{ }^{\circ} \mathrm{Na}\right]^{+}{ }^{\circ}$ ions $^{\circ}$ dominated ${ }^{\circ}$ and, under MALDI-PSD and -MS/MS conditions, fragmented through glycosidic and cross-ring cleavages to some extent, depending on the nature of the tag used. MALDI-MS/MS spectra of AB derivatives showed fragmentation patterns similar to those obtained by ESIMS/MS [16]. Higher $m / z$ fragment ${ }^{\circ}$ ions ${ }^{\circ}$ corresponded to $\mathrm{B}$ and $\mathrm{Y}$ cleavages, whereas for PHN and PMP deriva- tives, only B and C glycosidic cleavages were observed. $\mathrm{B}$ ions formed by loss of chitobiose seemed to undergo easier losses of residues from 3-linked mannose than from 6-linked mannose. Also, in the spectra of PHN derivatives, the abundance of ions corresponding to the cleavage of bisecting GlcNAc depended on the number of $^{\circ}$ residues $^{\circ}$ attached $^{\circ}$ to $^{\circ}$ the $^{\circ} 6$-antenna ${ }^{\circ}$ [30]..$^{\circ}$ Three GlcNAc residues attached directly to 6-mannose caused the most extensive loss of bisecting GlcNAc. Residues at the 6-position favored the loss of bisecting GlcNAc in the following decreasing order: (GlcNAc) ${ }_{3}$ Man-, Gal(GlcNAc) ${ }_{3}$ Man/(GlcNAc) ${ }_{2}$ Man-, GlcNAcMan-, Man-.

Differences were also noted in the abundances of cross-ring cleavage ions. While in all MS/MS spectra of PHN and PMP derivatives these types of ions were relatively abundant, corresponding peaks were either small or missing in the spectra of hybrid and complex AB glycans. Only MS/MS spectra of high mannose glycans contained cross-ring cleavage ion peaks of significant heights.

The following section shows and compares MALDIMS/MS spectra of hybrid, complex, galactosylated, and sialylated oligosaccharide derivatives. Fragmentation patterns observed in the tandem mass spectra of [M + $\mathrm{Na}]^{+}$of hybrid glycans $\left(\mathrm{MW}_{\text {native }} 1640.5\right)$ indicated the presence $^{\circ}$ of $^{\circ}$ three $^{\circ}$ isomers $^{\circ}\left(\right.$ Figure $\left.^{\circ} 9\right) .{ }^{\circ} \mathrm{Y}_{4}$ ions were 

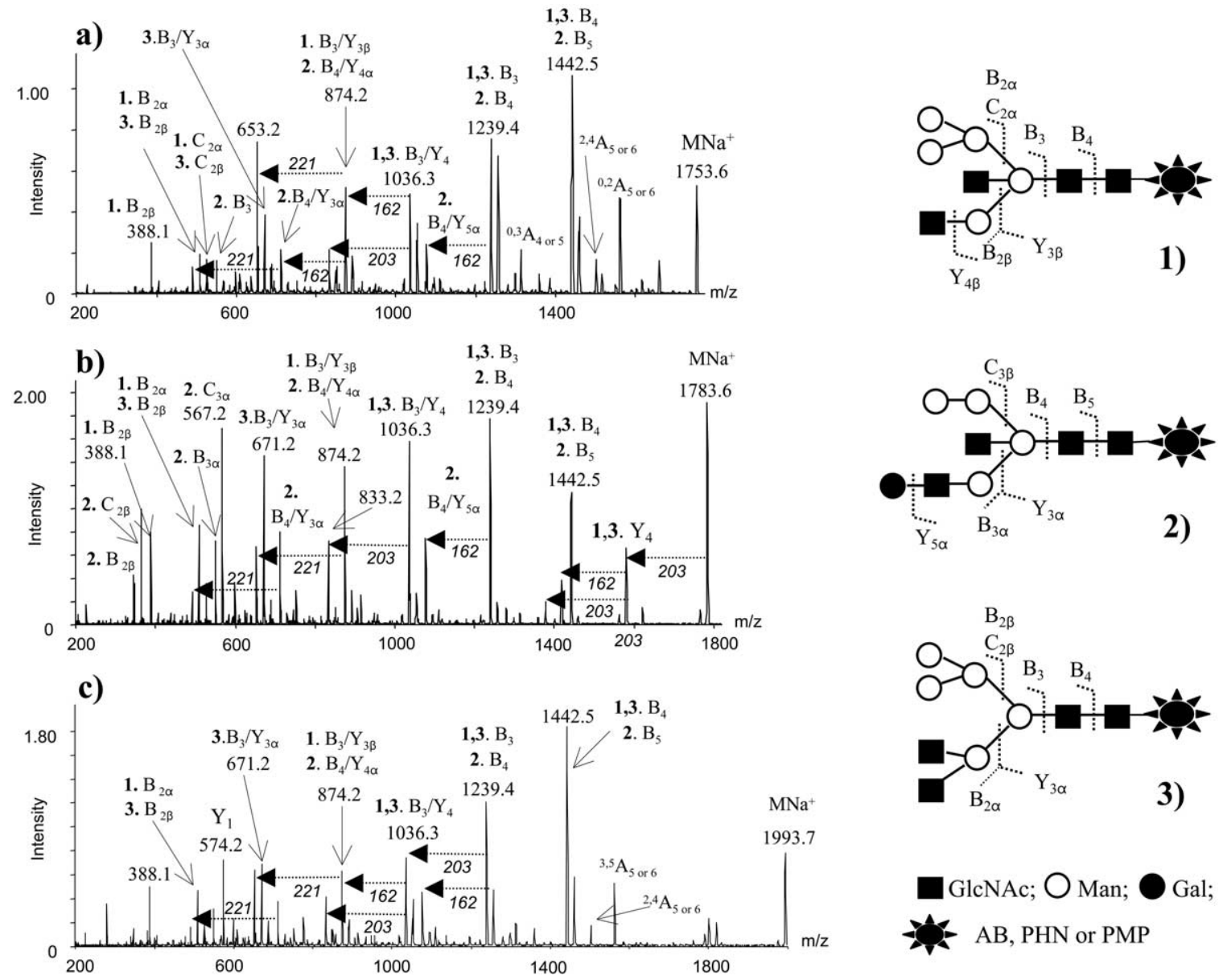

Figure 9. MALDI-MS/MS spectra of $[\mathrm{M}+\mathrm{Na}]^{+}$ions of hybrid glycans with $\mathrm{MW}_{\text {native }}$ 1663.5, obtained from ovalbumin and detected as (a) PHN, (b) AB-reduced, and (c) PMP derivatives. Fragment ions are sodiated.

consistent with the cleavage of a GlcNAc residue from the nonreducing end, and appeared as a large peak at $\mathrm{m} / \mathrm{z} 1580.6$ only in the spectrum of $\mathrm{AB}$ derivatives (Figure $9 \mathrm{~b}$ ). For ${ }^{\circ}$ Structure 1 , ' the ${ }^{\circ}{ }^{\circ}{ }^{\circ}$ of bisecting ${ }^{\circ} \mathrm{GlcNAc}$ $(-221 \mathrm{u})$ from $B_{3} / Y_{3 \beta}$ ions appeared at $m / z 653.2$ in the spectra of all three types of derivatives and were the most $^{\circ}$ abundant ${ }^{\circ}$ for ${ }^{\circ} \mathrm{PHN}$-glycans ${ }^{\circ}$ (Figure $\left.{ }^{\circ} 9 \mathrm{a}\right) . .^{\circ}$ In ${ }^{\circ}$ Figure $9 \mathrm{~b}^{\circ}\left(\mathrm{AB}^{\circ}\right.$ derivatives), ${ }^{\text {th }}$ this ${ }^{\circ}$ peak ${ }^{\circ}$ was ${ }^{\circ}$ masked ${ }^{\circ}$ by ${ }^{\circ}$ preferential loss of water from $B_{3} / Y_{3 \alpha}$ ions $(\mathrm{m} / z$ 671.3) in Structure 3, which has no bisecting moiety. In the case of Structure 2, the loss of bisecting GlcNAc appeared at $\mathrm{m} / \mathrm{z}$ 491.1. The presence of this latter isomer is also supported by cross-ring ${ }^{3,5} \mathrm{~A}_{3}$ ions at $m / z 599.3$, detected in all three spectra.

Figure ${ }^{\circ} 10^{\circ}$ presents $^{\circ}$ spectra ${ }^{\circ}$ of $^{\circ}$ complex $^{\circ}$ glycans $^{\circ}$ with $\mathrm{MW}_{\text {native }}$ 1722.5. Abundant $\mathrm{Y}_{4}$ ions appeared in the spectrum ${ }^{\circ}$ of $^{\circ} \mathrm{AB}^{\circ}$ derivatives $^{\circ}$ at $^{\circ} \mathrm{m} / \mathrm{z} 1662.6^{\circ}$ (Figure ${ }^{\circ} 10 \mathrm{~b}$ ), while in the other cases abundant ions corresponding to glycosidic cleavages from the reducing end were observed, $\mathrm{B}_{4}$ at ${ }^{\mathrm{C}} \mathrm{m} / \mathrm{z} 1524.5^{\circ}$ and ${ }^{\circ} \mathrm{B}_{3}$ at ${ }^{\mathrm{C}} \mathrm{m} / \mathrm{z} 1321.4^{\circ}$ (Figure $10 \mathrm{a}$, c). Peaks at $m / z 1159.3$ could arise from Structures 1 and 2 , according to cleavage patterns observed in the case of $\mathrm{AB}^{\circ}$ derivatized ${ }^{\circ}$ glycans $^{\circ}$ (Figure $10 \mathrm{~b}$ ). ${ }^{\circ}$ However ${ }^{\circ}$ the 9 large peak at $\mathrm{m} / \mathrm{z} 938.3$ in the spectrum of PHN-glycans is consistent with a loss of bisecting GlcNAc from $\mathrm{m} / \mathrm{z}$ $1159.3^{\circ}$ ions $^{\circ}\left(\text { Figure }^{\circ} 10 \mathrm{a}\right)^{\circ}$ and $^{\circ}$ could $^{\circ}$ be $^{\circ}$ assigned ${ }^{\circ}$ to Structure 3 . These ions with low abundances were also

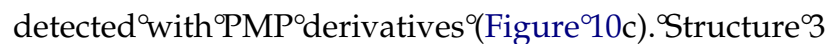
is also supported by the observation of $C_{2 \alpha}$ ions at $\mathrm{m} / \mathrm{z}$ 812.4 in the spectra of $\mathrm{PNH}$ and PMP derivatives. A PSD spectrum acquired after fractionation of the whole $\mathrm{PHN}^{\circ}$ derivatized ${ }^{\circ}$ glycan $^{\circ}$ pool $^{\circ}[30]^{\circ}$ provided $^{\circ}$ evidence for the presence of three isomers for (GlcNAc) ${ }_{6} \mathrm{Man}_{3}$ glycans.

The MALDI-MS/MS fragmentation patterns of all three types of derivatized, galactosylated complex glycans with $\mathrm{MW}_{\text {native }} 2290.8^{\circ}$ are shown in Figure 11 . In the spectra of PMP and PHN glycans, higher $\mathrm{m} / \mathrm{z}$ ions again corresponded to $\mathrm{B}, \mathrm{C}$, and cross-ring fragments ${ }^{3,5} \mathrm{~A}_{5}$ at $\mathrm{m} / \mathrm{z}$ 1963.7, ${ }^{0,2} \mathrm{~A}_{5}$ at $\mathrm{m} / \mathrm{z}$ 2009.7, and ${ }^{0,2} \mathrm{~A}_{6}$ at $\mathrm{m} / \mathrm{z} 2212.8$ (Figure $\left.^{\circ} 11 \mathrm{a},{ }^{\circ} \mathrm{C}\right){ }^{\circ}$ The $^{\circ}$ spectrum $^{\circ}$ of $^{\circ} \mathrm{AB}^{\circ}$ derivatives ${ }^{\circ}$ contained dominant $\mathrm{Y}$-type ions $\left(\mathrm{Y}_{4}\right.$ at $\left.\mathrm{m} / \mathrm{z} 2230.7\right)$. Further loss of GlcNAc or hexosyl from the nonreducing end produced $^{\circ}$ ions $^{\circ}$ at $^{\circ} \mathrm{m} / \mathrm{z} 2027.6^{\circ}$ and $^{\circ} 2068.6^{\circ}$ (Figure $^{\circ} 11 \mathrm{~b}$ ). The presence of bisecting GlcNAc in both isomers was apparent from the fragmentation pattern observed in 


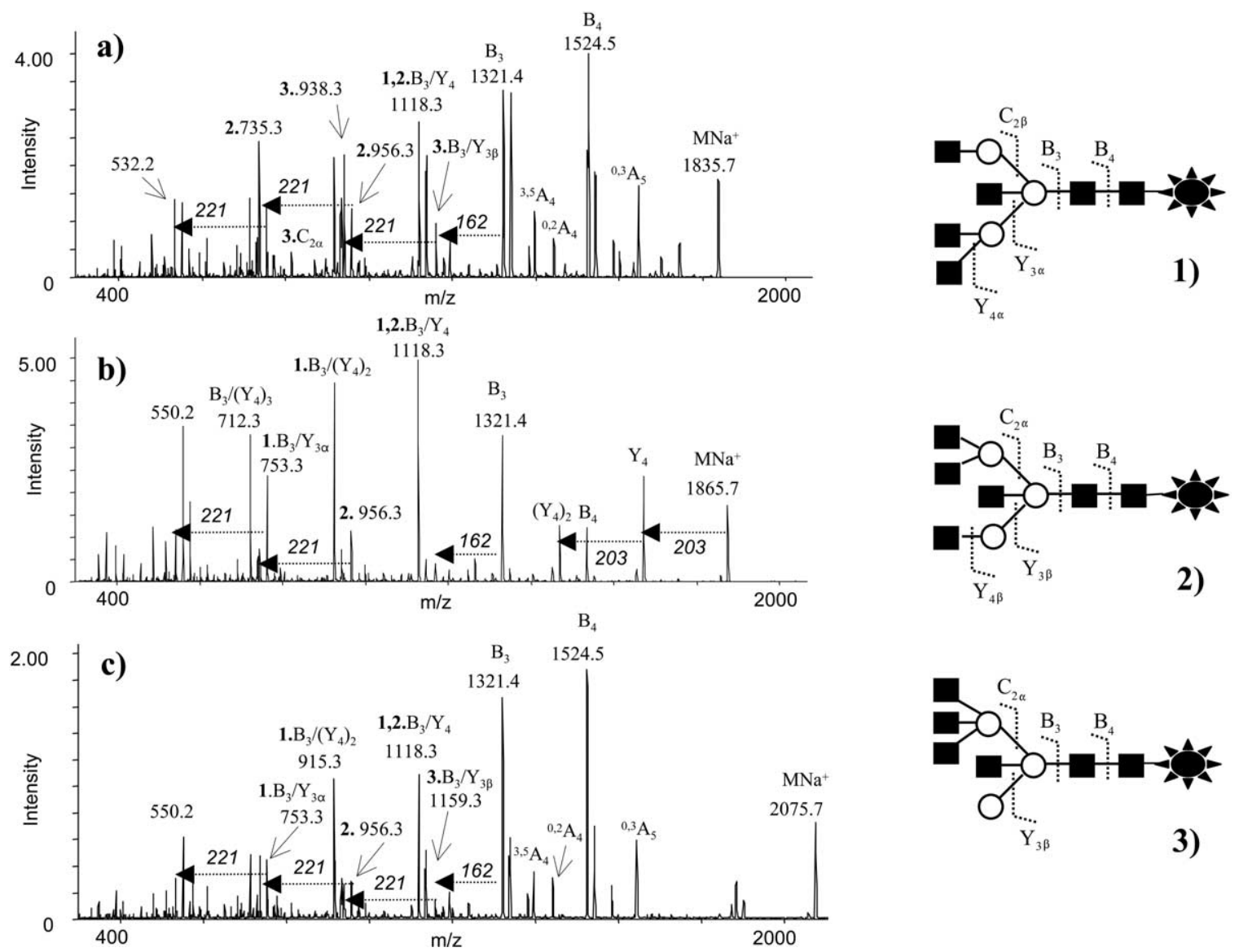

Figure 10. MALDI-MS/MS spectra of $[\mathrm{M}+\mathrm{Na}]^{+}$ions of complex PHN-glycans with $\mathrm{MW}_{\text {native }}$ 1745.5 obtained from hen ovalbumin and detected as (a) PHN, (b) AB-reduced, and (c) PMP derivatives. Fragment ions contain sodium.

the spectrum of PHN derivatives, where the loss of $221 \mathrm{u}$ from $\mathrm{B}_{3} / \mathrm{Y}_{3}$ ions appeared at $m / z 1100.4$ and 938.3. These cleavages were also present in the spectra of the other derivatives, although difficult to detect.

In the MS/MS spectra of high-mannose glycans (Scheme 3) other differences were noticed; for instance, $B$ and $C$ ions were absent from the spectra of $A B$ derivatives. Instead, abundant $Y_{1}$ and $Y_{2}$ ions appeared $(\mathrm{m} / \mathrm{z} 364.1$ and 567.2). Very abundant and diagnostically useful $\mathrm{B}_{3} / \mathrm{Y}_{3 \beta}$ ions, corresponding to the loss of chitobiose core and of the 3-antenna $(\mathrm{m} / \mathrm{z}$ 671.3), were observed in the spectra of $\mathrm{AB}$ and $\mathrm{PHN}$ glycans. For PMP derivatives, these signals were very weak and $Y_{1}$ fragments were the most abundant and dominated other ions.

MALDI-MS/MS spectra of biantennary sialylated fucosylated oligosaccharide $\mathrm{SA}(\mathrm{Gal})_{2}(\mathrm{GlcNAc})_{4}(\mathrm{Man})_{3} \mathrm{Fuc}$ $\left(\mathrm{MW}_{\text {native }} 2078.9\right)^{\circ}$ are $^{\circ}$ shown $^{\circ}$ in $^{\circ}$ Figure $^{\circ} 12 .^{\circ} \operatorname{In}^{\circ}$ all $^{\circ}$ three spectra the most abundant ions, $\mathrm{Y}_{6 \alpha}$, resulted from loss of sialic acid, but otherwise the spectra showed similar features as discussed earlier. Although $\mathrm{B}_{5} / \mathrm{Y}_{6 \alpha} / \mathrm{Y}_{3 \beta}$ ions at $\mathrm{m} / \mathrm{z} 712.3$ appeared in all spectra, only in the spectrum of the PHN derivative these ions showed favorable loss of water $^{\circ}\left(\mathrm{m} / \mathrm{z}\right.$ 694.2; ${ }^{\circ}$ Figure $\left.^{\circ} 12 \mathrm{a}\right){ }^{\circ}$ which $^{\circ}$ could $^{\circ}$ be $^{\circ}$ reliably assigned to loss of mannose from the 3-antenna. X-type fragments were present in the spectrum of the PHN derivative at $m / z$ 1971.7, 1708.6, 1343.4, 1313.3. The spectrum of the PMP derivative showed $X$ ions at $m / z$ 1947.6. In the spectrum of the $\mathrm{AB}$ derivative, these ions were absent. Relatively abundant A cross-ring cleavage ions were observed in the case of the PHN derivatives. These ions retained sialic acid and originated from loss of the chitobiose $^{\circ} \operatorname{core}^{\circ}\left(\mathrm{m} / \mathrm{z} 1633.6^{\circ}\right.$ and $^{\circ} 1806.5,{ }^{\circ}$ Figure $\left.^{\circ} 12 \mathrm{a}\right)$.

\section{Conclusions}

Variations in ESI/MALDI-MS sensitivity of derivatized carbohydrates depended on the choice of label and on the type of saccharide investigated. While epilactose showed enhanced sensitivity with PMP derivatization, lactose and fucosyllactose produced comparable peak heights with all three labels. For N-acetyllactosamine and sialyllactose, best signals were observed with $A B$ and PHN. Reduced AB derivatives of N-glycans after purification produced the highest signals. Desalting of $\mathrm{AB}$ and PMP derivatized mixtures after enzymatic cleavage and removal of excess derivatization agent were both very important. PHN labeling was advantageous in this view, as it allowed direct analysis, i.e., without sample cleanup. On the other hand, reduced 

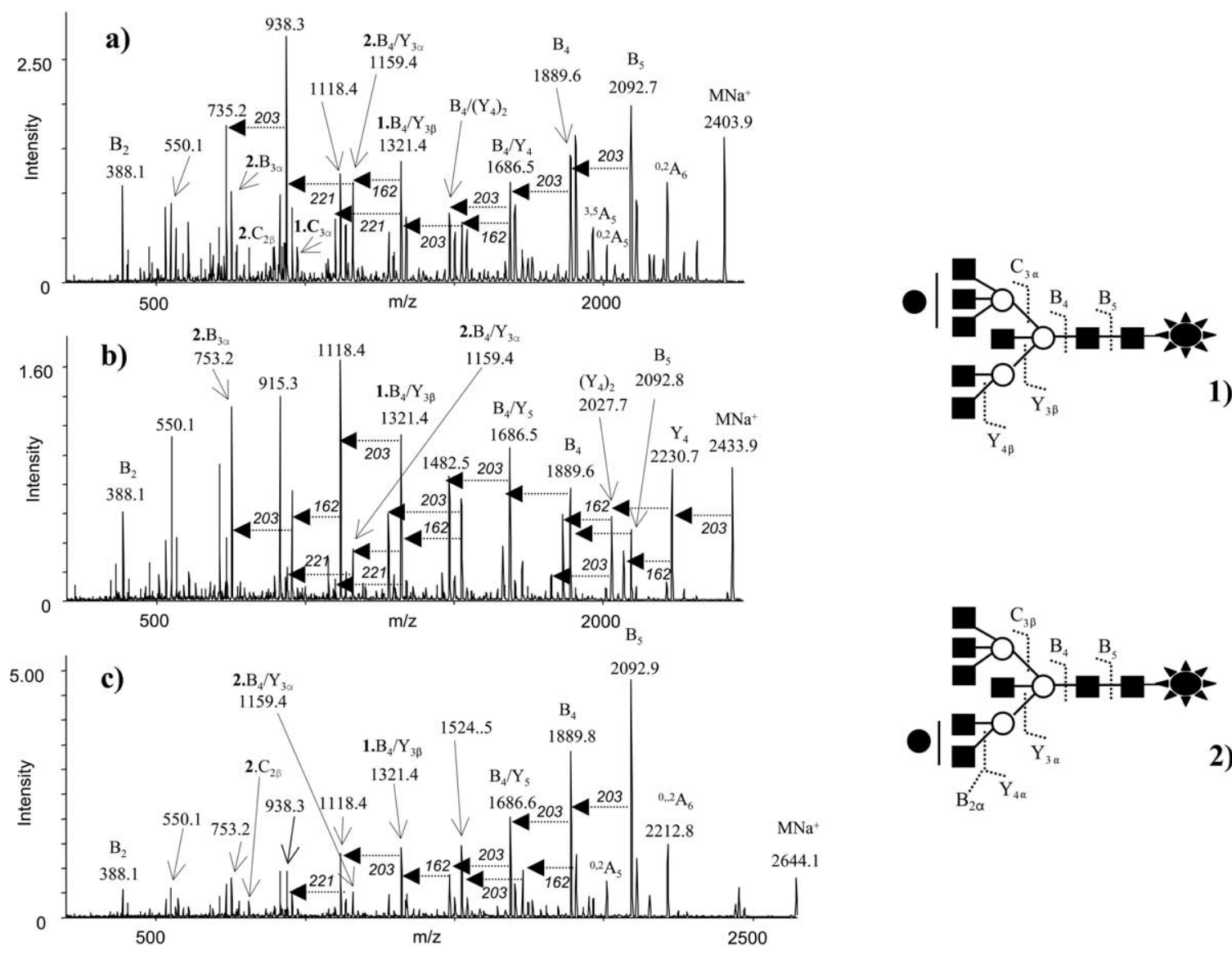

Figure 11. MALDI-MS/MS spectra of $[\mathrm{M}+\mathrm{Na}]^{+}$ions of galactosylated complex glycans with $\mathrm{MW}_{\text {native }} 2313.8$ from hen ovalbumin and detected as (a) PHN, (b) AB-reduced, and (c) PMP derivatives. Fragment ions contain sodium.

$\mathrm{AB}$ and PMP derivatives are more stable and their purification using cartridges is very handy. The cartridge cleanup procedure can be also used for unre-
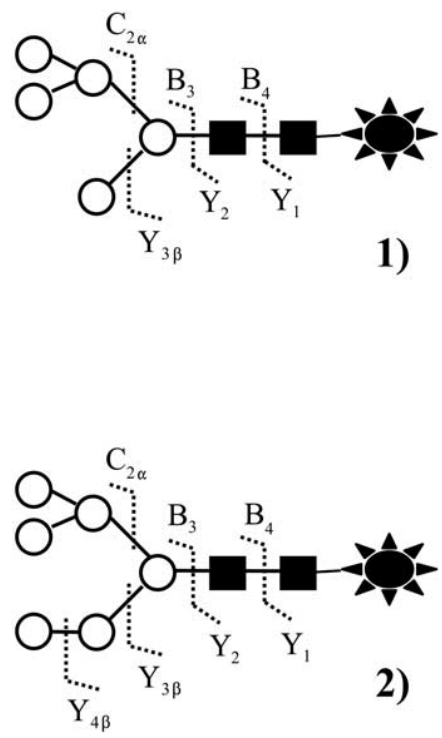

Scheme 3. Fragmentation scheme of $\mathrm{AB}, \mathrm{PMP}$ and $\mathrm{PHN}$ derivatives of high-mannose glycans, $\mathrm{MW}_{\text {native }} 1235$ (1) and 1437 (2). duced $\mathrm{AB}$ and PHN derivatives, when necessary, however yields are lowered.

As opposed to results shown in a previous study

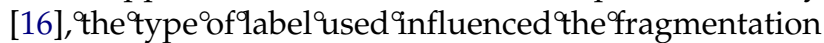
pattern observed by CID-MS/MS. In our hands, PMPand $\mathrm{AB}$-sialyllactose produced only Y-type ions under ESI/MALDI-MS/MS conditions. The ESI-MS/MS spectrum of PHN-sialyllactose was dominated by $\mathrm{B}$ and $\mathrm{Z}$ glycosidic cleavages. $B_{1}$ and $B_{2}$ fragments containing sialic acid were observed only in the spectra of native and PHN sialyllactose. In the MALDI spectrum of PHN sialyllactose, these ions appeared as $\mathrm{B}_{1}, \mathrm{C}_{2}$, and ${ }^{0,2} \mathrm{~A}_{6}$ cross-ring cleavages. The latter type of cleavage was also detected in the spectrum of the unreduced $A B$ derivative.

By MALDI-MS/MS, hybrid and complex N-glycans derivatized with PHN and PMP showed comparable glycosidic fragmentation patterns, while for AB-derivatives differences were observed. Here also, the most informative spectra were acquired with PHN derivatives, as $B_{x} / Y_{3}$ ions, consistent with losses of chitobiose core and 3-antenna, produced intense signals. These ions underwent loss of water in all oligosaccharides tested here. The abundance of ions corresponding to the cleavage of bisecting GlcNAc ( $-221 \mathrm{u})$ depended on the 

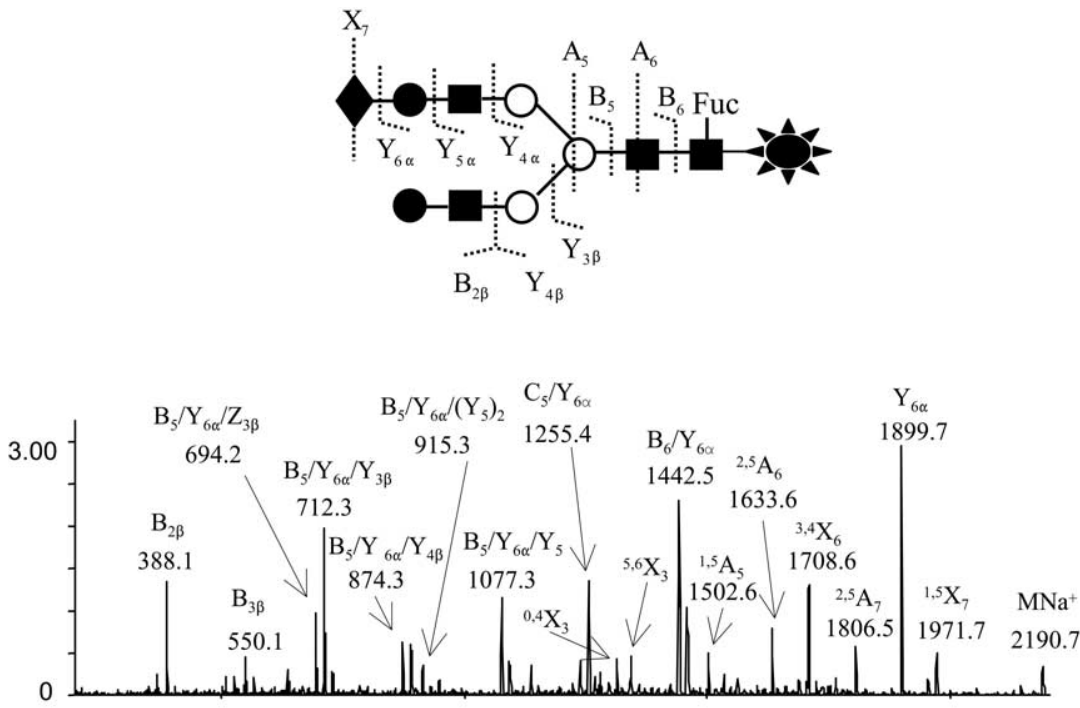

a)

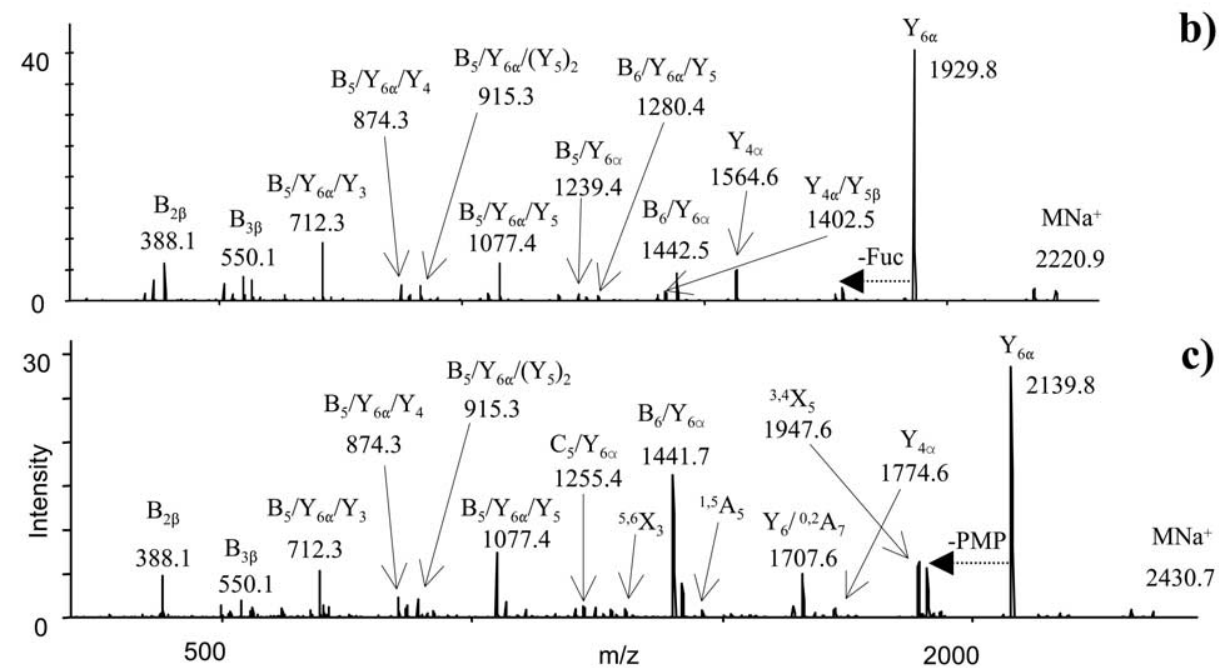

Figure 12. MALDI-MS/MS spectra of $[\mathrm{M}+\mathrm{Na}]^{+}$ions of sialylated biantennary fucosylated oligosaccharide with $\mathrm{MW}_{\text {native }} 2078.7$ and detected as PHN (a), AB-reduced (b), and PMP (c) derivatives. Fragment ions contain sodium.

number of residues linked to the 6-positioned mannose. Cross-ring cleavages, important to characterize linkages, produced relatively abundant ions. Spectra of some PMP derivatives showed this feature, but in the case of $A B$ derivatives these ions were mostly suppressed. For high-mannose N-glycans, AB and PHN produced the most useful fragmentation patterns. Highly favored Y-glycosidic cleavages from the reducing end of PMP derivatives suppressed the relative abundance of other ions.

\section{Acknowledgments}

The authors thank the Natural Sciences and Engineering Research Council of Canada (NSERC), the Canadian Foundation for Innovation (CFI), and the Canada Research Chair Program (CRC) for funding. They also thank K.G. Standing and W. Ens for the use of the MALDI-QqTOF instrument, and C. Lee and V. Chen for technical assistance and helpful discussions.

\section{References}

1. Iozzo, R. V. Crit. Rev. Biochem. Mol. Biol. 1997, 32, 141.

2. Helenius, A.; Aebi; M. Intracellular Function of N-Linked Gglycans. Science 2001, 291, 2364.

3. Dwek, R. A. Toward Understanding the Function of Sugars. Chem. Rev. 1996, 96, 683-720.

4. Lamari, F. N.; Kuhn, R.; Karamanos, N. K. Derivatization of Carbohydrates for Chromatographic, Electrophoretic, and Mass Spectrometric Structure Analysis. J. Chromatogr. B 2003, 793, 15-36.

5. Camilleri, P.; Tolson, D.; Birrell, H. Direct Structural Analysis of 2-Aminoacridone Derivatized Oligosaccharides by High-Performance Liquid Chromatography/Mass spectrometric detection. Rapid Commun. Mass Spectrom. 1998, 12, 144-148.

6. Okafo, G.; Burrow, L.; Carr, S. A.; Roberts, G. D.; Johnson, W.; Camilleri, P. A Coordinated High-Performance Liquid Chromatographic, Capillary Electrophoretic, and Mass Spectrometric Approach for the Analysis of Oligosaccharide Mixtures with 2-Aminoacridone. Anal. Chem. 1996, 68, 4424-4430. 
7. Charlwood, J.; Birrell, H.; Gribble, A.; Burdes, V.; Tolson, D.; Camilleri, P. A Probe for the Versatile Analysis and Characterization of N-Linked Oligosaccharides. Anal. Chem. 2000, 72, 1453-1461.

8. Takao, T.; Tambara, Y.; Nakamura, A.; Yoshino, K. I.; Fukuda, H.; Fukuda, M.; Shimonishi, Y. Sensitive Analysis of Oligosaccharides Derivatized with 4-Aminobenzoic Acid 2-(Diethylamino)Ethyl Ester by Matrix-Assisted Laser Desorption/Ionization Mass Spectrometry. Rapid Commun. Mass Spectrom. 1996, 10, 637-640.

9. Franz, A. H.; Molinski, T. F.; Lebrilla, C. B. MALDI-FTMS Characterization of Oligosaccharides Labeled with 9-Aminofluorene. J. Am. Soc. Mass Spectrom. 2001, 12, 1254-1261.

10. Hase, S.; Ibuki, T.; Ikenaka, T. Reexamination of the Pyridylamination Used for Fluorescence Labeling of Oligosaccharides and its Application to Glycoproteins. J. Biochem. (Tokyo) 1984, 95, 197-203.

11. Okamoto, M.; Takahashi, K.; Doi, T.; Takimoto, Y. HighSensitivity Detection and Postsource Decay of 2-Aminopyridine-Derivatized Oligosaccharides with Matrix-Assisted Laser Desorption/Ionization Mass Spectrometry. Anal. Chem. 1997, 69, 2919-2926.

12. Suzuki, S.; Kakehi, K.; Honda, S. Comparison of the Sensitivity of Various Derivatives of Oligosaccharides in LC/MS with Fast Atom Bombardment and Electrospray Ionization Interfaces. Anal. Chem. 1996, 68, 2073-2083.

13. Bigge, J.; Patel, T. P.; Bruce, J. A.; Goulding, P. N.; Charles, S. M.; Parekh, R. B. Nonselective and Efficient Fluorescent Labeling of Glycans Using 2-Aminobenzamide and Anthranilic Acid. Anal. Biochem. 1995, 230, 229-238.

14. Harvey, D.J . Collision-Induced Fragmentation of 2-Aminobenzamide-Labeled Neutral N-Linked Glycans. Analyst 2000, 125, 609-617.

15. Anumula, K. R.; Dhume, S. T. High Resolution and High Sensitivity Methods for Oligosaccharide Mapping and Characterization by Normal Phase High Performance Liquid Chromatography Following Derivatization with Highly Fluorescent Anthranilic Acid. Glycobiology 1998, 8, 685-694.

16. Harvey, D. J. Electrospray Mass Spectrometry and Fragmentation of N-Linked Carbohydrates Derivatized at the Reducing Terminus. J. Am. Soc. Mass Spectrom. 2000, 11, 900-915.

17. Ojala, W. H.; Ostman, J. M.; Ojala, C. R. Schiff Bases or Glycosylamines: Crystal and Molecular Structures of Four Derivatives of D-Mannose. Carbohydr. Res. 2000, 326, 104-112.

18. Li, D. T.; Her, G. R. Structural Analysis of ChromophoreLabeled Disaccharides and Oligosaccharides by Electrospray Ionization Mass Spectrometry and High-Performance Liquid Chromatography/Electrospray Ionization Mass Spectrometry. J. Mass Spectrom. 1998, 33, 644-652.
19. Li, D. T.; Shenn, J. F.; Her, G. R. Structural Analysis of Chromophore-Labeled Disaccharides and Oligosaccharides by Capillary Electrophoresis Tandem Mass Spectrometry Using Ion Trap Mass Spectrometry. J. Am. Soc. Mass Spectrom. 2000, 11, 292-300.

20. Zaia, J.; Li, X. Q.; Chan, S. Y.; Costello, C. Tandem Mass Spectrometric Strategies for Determination of Sulfation Position and Uronic Acid Epimerization in Chondroitin Sulfate Oligosaccharides. J. Am. Soc. Mass Spectrom. 2003, 14, 12701281.

21. Strydom, D. J. Chromatographic Separation of 1-Phenyl-3Methyl-5-Pyrazolone-Derivatized Neutral Acidic and Basic Aldoses. J. Chromatogr. A 1994, 678, 17.

22. Shen, X.; Perreault, H. Characterization of Carbohydrates Using a Combination of Derivatization, High-Performance Liquid Chromatography and Mass Spectrometry. J. Chromatogr. A 1998, 811, 47-59.

23. Lattova, E.; Perreault, H. Labeling Saccharides with Phenylhydrazine for Electrospray and Matrix-Assisted Laser Desorption-Ionization Mass Spectrometry. J. Chromatogr. B 2003, 793, 167-179.

24. Lattova, E.; Perreault, H. Profiling of N-Linked Oligosaccharides Using Phenylhydrazine Derivatization and Mass Spectrometry. J. Chromatogr. A 2003, 1016, 71-87.

25. Lattova, E.; Petrus, L. Synthesis of N-Acetyl-Lactosamine via Ozonolysis of a Nitro Derivative. Carbohydr. Res. 1992, 235, 289-293.

26. Tarentino, A. L.; Plummer, T. H. Enzymatic Deglycosylation of Asparagine-Linked Glycans: Properties and Specificity of Oligosaccharide Cleaving Enzymes from Flavobacterium meningosepticum. Methods in Enzymology 1994, 230, 44-57.

27. Tarentino, A. L.; Gomez, C. M.; Plummer, T. H. Deglycosylation of Asparagines-Linked Glycans by Peptide: N-Glycosidase F. Biochemistry 1985, 24, 4665-4671.

28. Loboda, A. V.; Krutchinsky, N. N.; Bromirski, M. P.; Ens, W.; Standing, K. G. A Tandem Quadrupole/Time-of Flight Mass Spectrometer with a Matrix-Assisted Laser Desorption/Ionization Source: Design and Performance. Rapid Commun. Mass Spectrom. 2000, 14, 1047-1057.

29. Domon, B.; Costello, C. E. A Systematic Nomenclature for Carbohydrate Fragmentations in FABMS/MS Spectra of Glycoconjugates. Glycoconj. J. 1988, 5, 397-409.

30. Lattova, E.; Perreault, H.; Krokhin, O. Matrix-Assisted Laser Desorption/Ionization Tandem Mass Spectrometry and PostSource Decay Fragmentation Study of Phenylhydrazones of $\mathrm{N}$-Linked Oligosaccharides from Ovalbumin.J. Am. Soc. Mass Spectrom. 2004, 15, 725-735. 